\title{
Evaluation of Tooth Wear and its Causative Risk Factors Amongst Patients Attending Dental Hospital of Karachi
}

\author{
Aneeqa Shahab ${ }^{1}$ \\ Aisha Wali \\ Talha M Siddiqui ${ }^{3}$ \\ Mobeen Hamed ${ }^{4}$ \\ Kiran Aslam 5
}

\author{
BDS, MME (scholar) \\ BDS, MPH, PhD (scholar) \\ BDS, MCPS, MME \\ BDS \\ BDS
}

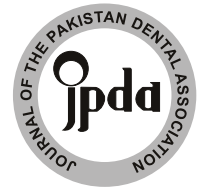

OBJECTIVE: Tooth wear is a term defined as the loss of dental hard tissue in a damaged tooth if there is no existing dental caries or trauma. Tooth wear rarely exists alone and is observed clinically and experimentally in combination. Excessive tooth wear leads to hypersensitivity and exposed dentin. Tooth wear can be classified as attrition, erosion, abrasion. The frequency of normal tooth preservation is greater than ever, thus a better prevalence of tooth wear is experiential in the population. Therefore, the objective of the present cross-sectional study was to evaluate tooth wear and its causative risk factors amongst patients attending the Dental Hospital of Karachi.

METHODOLOGY: The current study was a cross-sectional study conducted on adult patients recruited from the Out-Patient Department of Oral Diagnosis from May 2018 - December 2018. A consecutive sampling method was used and 250 adult patients aged 18-45 years were included. Tooth wear was assessed by using Smith and Knight Tooth Wear Index (TWI index).Data was entered and analyzed by using SPSS, frequency, percentages were calculated, and a chi-square test was performed to find the association between gender and risk factors.

RESULTS: The subject populations of 250 were assessed. Out of which 178 were male $(71.2 \%)$ and $72(28.8 \%)$ were female with age ranging between 18 to 48 years old. In this study, $92.4 \%$ of them were suffering from tooth wear and only $31.2 \%$ have extended to the severe stage of the tooth surface loss.

CONCLUSION: The present study concluded that there is an association between tooth wear and its risk factors.

KEYWORDS: Tooth Wear; Dental Wear; Tooth Wear Indices; Sensitivity and Specificity; Risk Factors.

HOW TO CITE: Shahab A, Wali A, Siddiqui TM, Hamed M, Aslam K. Evaluation of tooth wear and its causative risk factors amongst patients attending dental hospital of Karachi. J Pak Dent Assoc 2021;30(4):255-260.

DOI: https://doi.org/10.25301/JPDA.304.255

Received: 06 January 2021, Accepted: 07 August 2021

\section{INTRODUCTION}

$\mathrm{T}$ ooth wear is a term defined as the loss of dental hard tissue in a damaged tooth if there is no existing dental caries or trauma. ${ }^{1}$ Tooth wear can be sub-classifies as attrition, erosion, abrasion and abfraction. ${ }^{2}$ Attrition is a mechanical type of wear, which results due to the grinding of teeth. Abrasion is also mechanical wear caused by oral hygiene measures and biting habits. Erosion is chemical wear that results from the ingestion of acidic foods /drinks/ gastroesophageal reflux..$^{3-5}$ Abfraction is a non

1. Registrar, Department of Operative Dentistry, Baqai Dental College, BMU.

2. Assistant Director Research. Department of Research \& Development, Baqai Dental College, BMU.

3. Associate Professor, Department of Operative Dentistry, Baqai Dental College, BMU.

4. House Surgeon, Department of Operative Dentistry, Baqai Dental College, BMU.

5. House Surgeon, Department of Operative Dentistry, Baqai Dental College, BMU.

Corresponding author: "Dr. Aneeqa Shahab” < Aneeqa.shahab@gmail.com > carious tooth loss which is characterized by v shaped notch or wedge shaped at the cervical area of tooth.

These types of wear rarely exist alone and are observed clinically and experimentally in combination. ${ }^{6}$ It might be unnoticeable in its initial developmental stage but it may affect aesthetics and appearance in some patients especially if anterior teeth are involved. ${ }^{7,8}$ Excessive tooth wear leads to hypersensitivity and exposed dentin. ${ }^{9}$

The prevalence of tooth wear varies with wide-ranging values reported due to different study populations, methodologies, recording indices used. ${ }^{10}$ These studies reported that the prevalence of tooth wear varies from one population to another. It was reported $38.6 \%$ in Pakistani population ${ }^{11}, 64 \%$ in Norway ${ }^{12,13} 75 \%$ in Sweden ${ }^{14}$ and $95 \%$ in Saudi Arabia. ${ }^{7}$

There are many techniques to measure tooth wear both in vitro and in vivo. Techniques to quantify tooth wear in 
vitro are profilometry, microradiography, scanning electron microscopy, atom force microscopy, nano- and microhardness test, iodide permeability test. ${ }^{15,16}$ To measure tooth wear in vivo, many indices are used like the Eccles index of dental erosion, Smith and Knight index, and Erosion index by Lussi. ${ }^{17}$ Some of these indices measure tooth wear on every surface of each tooth, some measures selected sites and specific surfaces. ${ }^{17}$ Smith and Knight ${ }^{19}$ introduced tooth wear index (TWI) which is capable of measuring all four visible surfaces (buccal, cervical, lingual, and occlusalincisal) of all teeth present. Except for a few studies, not much work has been done in Pakistan on this topic. Toufique $\mathrm{H}$ et al $2017^{19}$ in a study reported that only $10 \%$ of the patients had tooth wear whereas in the present study $92.4 \%$ of them had tooth wear. Therefore, the present cross-sectional study was done to Evaluate Tooth wear and its causative risk factors amongst Patients Attending the Dental Hospital of Karachi.

\section{METHODOLOGY}

The current study was a cross-sectional study conducted on adult patients recruited from the Out-Patient Department of Oral Diagnosis from May 2018 - December 2018. Patients were examined for the presence of tooth surface loss by using the Tooth Wear Index (TWI). The Ethical Review Board (ERB ) DC/ERB/2018/010), Baqai Dental College, gave ethical approval to proceed with this study. Patients with the complaint of tooth surface loss aged 18-45 years were included in the study.A consecutive sampling technique was used and 250 adult patients were selected for the study. Open Epi version 3.01software was used to calculate the sample size. Keeping a $20 \%$ prevalence rate with a $95 \%$ confidence interval with a 5\% error, $n=250$ sample size was calculated based on the prevalence tooth wear reported by Daly et al. ${ }^{20}$

Oral and Dental examinations were performed using the dental chair with a sterile mouth mirror and dental probe after signing a written consent by the patient. The chief examiner examined the patients while the dental chair assistant recorded the readings. A structured questionnaire prepared by those skilled in the restorative subject was used, which included etiological aspects of parafunctional habits, oral hygiene measures, eating habits, and clinical history. Tooth wear was assessed by using Smith and Knight Tooth Wear Index (TWI index). ${ }^{18}$ The surfaces were designated as cervical surface (C), buccal surface (B), the lingual surface (L) or palatal surface (P) Incisal surface (I) or, occlusal surface (O). Patients who reported having symptoms of sensitivity were further assessed by a blast of air from the air-water syringe for $3 \mathrm{sec}$ at a distance of $1 \mathrm{~cm}$ from the tooth surface.
Any uncomfortable feeling aroused by the blast was recorded on the clinical form according to different tooth surfaces. ${ }^{21}$ Data was entered and analyzed for Descriptive analysis (frequency and percentages). A Chi-square test was performed to assess the association between gender and its etiological factors by using IBM SPSS version 20 .

\section{RESULTS}

The subject populations of 250 adult patients were assessed for tooth surface loss by using the Tooth wear index. According to Smith and Knight TWI, 2010 ${ }^{18}$ reported that $7.6 \%$ scored $0,11.6 \%$ scored $1,24.4 \%$ scored $2,25.2 \%$ scored 3 and $31.2 \%$ scored 4 . Out of which 178 were male (71.2\%) and $72(28.8 \%)$ were females aged 18 to 48 years old. Table 1 showed the Demographic profile.

In table 2,association of gender with etiological factors is mentioned which shows insignificant association that is $42(23.6 \%)$ males and 17 (23.6\%) females reported sensitivity, followed by $20(11.2)$ males and $9(12.5 \%)$ females with poor previous tooth aesthetics. $(\mathrm{p}=0.535), 33(18.5 \%)$ of males and $19(26.4 \%)$ females reported a history of scaling. $(\mathrm{p}=0.110)$. A significant association was seen when 89

Table 1: Demographic profile

\begin{tabular}{|l|c|}
\hline \multicolumn{1}{|c|}{ Tooth wear } & n(\%) \\
\hline \multicolumn{1}{|c|}{$\begin{array}{l}\text { Male } \\
\text { Female }\end{array}$} & $\mathbf{2 5 0}$ \\
Age & $72(28.8 \%)$ \\
18-28 years & \\
$29-39$ years & $66(26.4 \%)$ \\
40-50 years & $82(32.8 \%)$ \\
Total patients examined with & $102(40.8 \%)$ \\
Smith \& Knight Tooth Wear & \\
index & \\
Score 0 & \\
Score 1 & \\
Score 2 & \\
Score 3 & $19(7.6 \%)$ \\
Score 4 & $29(11.6 \%)$ \\
\hline
\end{tabular}


Shahab A/ Wali A/ Siddiqui TM/ Hamed M/ Aslam K

Table 2: Association of gender with etiological factors

\begin{tabular}{|c|c|c|c|}
\hline Variables & Male & Female & p-value \\
\hline $\begin{array}{l}\text { Does patient complaint of } \\
\text { - Dentin sensitivity } \\
\text { - } \text { Tooth fracture } \\
\text { - Poor masticatory function } \\
\text { - } \text { Poor esthetics of anterior teeth } \\
\text { - } \text { All } \\
\text { - No complaint }\end{array}$ & $\begin{array}{l}42(23.6 \%) \\
8(4.5 \%) \\
12(6.7 \%) \\
20(11.2 \%) \\
96(53.9 \%) \\
0\end{array}$ & $\begin{array}{l}17(23.6 \%) \\
4(5.6 \%) \\
2(2.8 \%) \\
9(12.5 \%) \\
39(54.2 \%) \\
1(1.4 \%)\end{array}$ & 0.53 \\
\hline $\begin{array}{l}\text { Dental history of } \\
\text { - } \text { Porcelain veneers } \\
\text { - } \text { Bleaching } \\
\text { - Scaling } \\
\text { - No history }\end{array}$ & $\begin{array}{l}11(6.2 \%) \\
2(1.1 \%) \\
33(18.5 \%) \\
132(74.2 \%)\end{array}$ & $\begin{array}{l}0 \\
1(1.4 \%) \\
19(26.4 \%) \\
52(72.2 \%)\end{array}$ & 0.11 \\
\hline 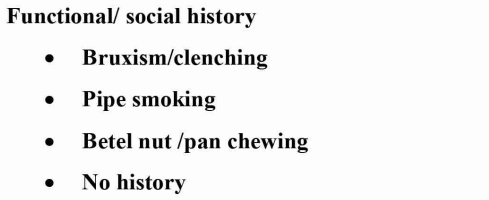 & $\begin{array}{l}15(8.4 \%) \\
25(14 \%) \\
89(50 \%) \\
49(27.5 \%)\end{array}$ & $\begin{array}{l}4(5.6 \%) \\
4(5.6 \%) \\
24(33.3 \%) \\
40(55.6 \%)\end{array}$ & $<0.00$ \\
\hline $\begin{array}{l}\text { Brushing technique } \\
\text { - Vertical } \\
\text { - Horizontal } \\
\text { - Circular } \\
\text { - Combination }\end{array}$ & $\begin{array}{l}7(9.7 \%) \\
121(68 \%) \\
7(3.9 \%) \\
43(24.2 \%)\end{array}$ & $\begin{array}{l}7(9.7 \%) \\
52(72.2 \%) \\
1(1.4 \%) \\
12(16.7 \%)\end{array}$ & 0.13 \\
\hline $\begin{array}{l}\text { Bristles stiffness } \\
\begin{array}{l}\text { - } \\
\text { - } \\
\text { - } \\
\text { - Sodium } \\
\text { - } \\
\text { No brushing }\end{array}\end{array}$ & $\begin{array}{l}18(10.1 \%) \\
76(42.7 \%) \\
40(22.5 \%) \\
44(24.7 \%)\end{array}$ & $\begin{array}{l}7(9.7 \%) \\
27(37.5 \%) \\
25(34.7 \%) \\
13(18.1 \%)\end{array}$ & 0.23 \\
\hline $\begin{array}{l}\text { How much force you apply while brushing teeth } \\
\text { - } \text { Mild } \\
\text { - Moderate } \\
\text { - Aggressive } \\
\text { - } \quad \text { Not accessed }\end{array}$ & $\begin{array}{l}18(10.1 \%) \\
76(42.7 \%) \\
40(22.5 \%) \\
44(24.7 \%)\end{array}$ & $\begin{array}{l}7(9.7 \%) \\
25(34.7 \%) \\
27(26.8 \%) \\
13(18.1 \%)\end{array}$ & 0.105 \\
\hline $\begin{array}{l}\text { How much time you spent brushing of teeth } \\
\begin{array}{l}\text { - } 30 \mathrm{sec} \\
\text { - } 1 \mathrm{~min} \\
\text { - } 2 \mathrm{~min} \\
\text { - } 3 \mathrm{~min}\end{array}\end{array}$ & $\begin{array}{l}1(0.6 \%) \\
14(7.9 \%) \\
68(38.2 \%) \\
51(28.7 \%)\end{array}$ & $\begin{array}{l}2(1.2 \%) \\
9(12.5 \%) \\
29(40.3 \%) \\
19(26.4 \%)\end{array}$ & 0.349 \\
\hline
\end{tabular}

Table 3: Association between Age and Dentinal sensitivity

\begin{tabular}{|c|c|c|c|}
\hline \multirow{2}{*}{ Age } & \multicolumn{2}{|c|}{ Dentinal sensitivity } & \multirow{2}{*}{ p-value } \\
\cline { 2 - 3 } & No & $\%$ & \\
\hline $18-28$ & 16 & $27.1 \%$ & \multirow{2}{*}{0.10} \\
\hline $29-39$ & 21 & $35.6 \%$ & \\
\hline $40-50$ & 22 & $37.3 \%$ & \\
\hline
\end{tabular}

Evaluation of tooth wear and its causative risk factors amongst patients attending dental hospital of Karachi

(50\%) of males and 24 (33.3\%) of women had a history of $\mathrm{pan} /$ betel nut chewing, $(\mathrm{p}<0.001)$. No significant association was reported regarding toothbrush technique and 121 (68\%) men and $52(72.2 \%)$ women used horizontal brush technique $(\mathrm{p}=0.136)$

Regarding tooth wear and dentin sensitivity, it was found that dentinal sensitivity increased with the age group. This difference was not found to be statistically significant. $(\mathrm{p}=0.10)$ Table 3 .

It was found that tooth wear increased with age group. For the age group, 18-28, 29-39 and 40-50 scores 2 and 4,

Table 4: Association between age and tooth wear index

\begin{tabular}{|c|c|l|l|l|l|l|}
\hline \multirow{2}{*}{ Age } & \multicolumn{5}{|c|}{ Smith \&Knight tooth wear index } & \multirow{2}{*}{ p-value } \\
\cline { 2 - 6 } & Score 0 & Score 1 & Score 2 & Score 3 & Score 4 & \\
\hline $18-28$ & $11(16.7 \%)$ & $11(16.7 \%)$ & $19(28.2 \%)$ & $12(18.2 \%)$ & $13(19.7 \%)$ & \\
\cline { 1 - 5 } $29-39$ & $6(7.3 \%)$ & $8(9.8 \%)$ & $23(28 \%)$ & $23(28 \%)$ & $22(26.8 \%)$ & \multirow{2}{*}{$<0.00$} \\
\cline { 1 - 5 } $40-50$ & $2(2 \%)$ & $10(9.8 \%)$ & $19(18.6 \%)$ & $28(27.5 \%)$ & $43(42.2 \%)$ & \\
\hline
\end{tabular}

2nad 3, 3 and 4 were prevalent respectively. The difference was statistically significant $(\mathrm{p}=0.000)$ Table 4 .

\section{DISCUSSION}

The present study was done to evaluate tooth surface loss in patients attending the Out-Patient Department of Baqai Dental College. In this study, $92.4 \%$ of them reported tooth wear and only $31.2 \%$ has extended to severe stage of the tooth wear and men reported severe tooth wear than women did.

A study done in the Dutch population reported that tooth surface loss was a common condition amongst the adult population. ${ }^{22}$ In this present study, $7.6 \%$ of participants reported no tooth surface loss and $92.4 \%$ of them reported tooth wear however, only $31.2 \%$ had reached to severe stage of tooth wear. Toufique $\mathrm{H}$ et al. in $2017^{19}$ reported dissimilar results that only $10 \%$ of participants had tooth wear while $90 \%$ did not have tooth wear in their study. A study by Van't Spijker ${ }^{23}$ reported the frequency of patients with tooth surface loss was increased to $3 \%$ at the age of 20 years, $17 \%$ increased at 70 years of age.

The present study according to Smith and Knight TWI, $2010{ }^{18}$ reported that $7.6 \%$ scored $0,11.6 \%$ scored 1 , $24.4 \%$ scored 2, 25.2\% scored 3 and $31.2 \%$ scored 4 . R Wirdatul et $\mathrm{al}^{24}$ in a study reported different values, $17.4 \%$ surfaces had tooth wear; $80 \%$ scored 1, $18 \%$ scored 2 and $2 \%$ scored 3 . Oral habits are repetitive behaviors within the oral range, leading to loss of dental structure, such as eating habits, brushing techniques, bruxism, functional habits, and regurgitation. The effect depends on the nature, manifestation, and duration of the habit. The role of acids in food and 
beverages can be important in the development of toot wear. Laboratory studies have shown that low acid foods and beverages cause erosion of enamel and dentin which may lead to dentin sensitivity. ${ }^{25-27}$

Dentinal hypersensitivity (DH) is a common symptom which affects $8-57 \%$ of adult and is associated with the oral hygiene. ${ }^{28}$ The present study reported an association of tooth wear with dentin hypersensitivity and age groups. Deshpande $\mathrm{S}^{29}$ in a study reported that there is a connection between grades of tooth wear with dentin sensitivity. Ayer A et $\mathrm{al}^{30}$ in a study reported that dentin hypersensitivity is associated with tooth surface loss. Idon $\mathrm{P}$ et $\mathrm{al}^{31}$ in a study reported an association of dentin hypersensitivity with tooth surface loss. Kehua Q et al. ${ }^{21}$ in a study reported that there is an association between dentin hypersensitivity and age groups. Ali $\mathrm{K}$ et al. ${ }^{32}$ find abnormal tightening and bruxism with a significant relationship with tooth surface loss. The present study reported that only $7.6 \%$ experienced tooth surface loss due to tightening/ bruxism, while $45.2 \%$ experienced tooth surface loss due to chewing pan. As tooth surface loss is multifactorial, therefore the abrasive effect of tooth brushing can cause a tooth surface loss. The present study reported that people using a brush with medium bristles $(41.2 \%)$ in horizontal technique $(69.2) \%$ with medium force (40.4) \% tend to have more tooth surface loss which shows a correlation with the study reported by Ahmed et $\mathrm{al}^{32}$ that brushing with moderate type of brush (48.4) \% shows relevant tooth surface loss. Another study reported by Mushtaq et al. ${ }^{33}$ also observed a substantial association between participants using different types of toothbrushes and hard tissue abrasive lesions was reported $(\mathrm{p}<0.05)$. The cause of these injuries is important to prevent further injuries and to prevent existing injuries. Enamel reduced by acids (erosion), may be scrubbed away with tooth brushing (abrasion) and damaged away by chewing or tooth grinding. ${ }^{25}$

Males in the present study were more liable to have tooth surface loss possibly due to majority of males assessed as compared to females and this result was similar to other various studies. ${ }^{7,34,35}$ The factors which result in more tooth surface loss in males were mainly due to age, biting force, reduced tendency for malocclusion, more muscle mass, decreased occlusal tactile sensitivity. ${ }^{36,37}$

Generally, patients are more concerned about their esthetics and wish that their age process could be delayed and evidence revealed that tooth wear is related to the aging process. ${ }^{28}$ The present study reported that tooth wear increase with increasing age. Deshpande $\mathrm{S}^{28}$ and Meshramkar $\mathrm{R}^{38}$ et al. in a study also reported similar results.

Proper steps need to be taken for immediate action, as they are essential to restore the form and function of teeth. Dental wear is a preventive and curable condition. To avoid the problem of getting worse in the future, we must try to fight the problem from its early stages. One of the methods to prevent and cure the condition is to increase awareness among practitioners and to develop general public prevention programs among individuals. The present study has some limitations, which include that it was a single centre study, there were more male participants, and lacks the inclusion of other demographic variables. Evaluation of tooth wear should be added as a component of regular dental checkups amongst patients attending dental hospitals.

\section{CONCLUSIONS}

Recognizing the multifactorial nature of the condition is the first step in managing it, as a misunderstanding, it can lead to inadequate management and the ultimate failure of rehabilitation therapy. The present study concluded that tooth surface loss is associated with its etiological factors and was observed more in males when compared to females. However, steps should be taken to increase awareness among people regarding their teeth and the management of several conditions.

\section{CONFLICT OF INTEREST}

None to declare

\section{ETHICS APPROVAL /DISCLOSURE}

The study Titled "A cross-sectional study: Evaluation of Tooth wear and its causative risk factors amongst Patients Attending Dental Hospital of Karachi." is approved by the Ethical Review Board of Baqai Dental College under the reference \# BDC/ERB/2018/010.

\section{AUTHORS CONTRIBUTIONS}

AS contributed in writing and tabulating research paper AW analyzed and interpreted the patients' data TMS provided overall supervision MH and KA contributed to the collection of patients' data.

\section{ACKNOWLEDGMENTS}

Thanks to the institution for supporting the study.

\section{EFERENCES}

1. Liu B, Zhang M, Chen Y, Yao Y. Tooth wear in aging people: an investigation of the prevalence and the influential factors of incisal/occlusal tooth wear in northwest China. BMC Oral Health 2014; 14: 65.

https://doi.org/10.1186/1472-6831-14-65 
Shahab A/ Wali A/ Siddiqui TM/ Hamed M/ Aslam K

2. Lopez-Frias FJ, Castellanos-Cosano L, Martín-González J, LlamasCarreras JM, Segura-Egea JJ. Clinical measurement of tooth wear: tooth wear indices. J Clin Exp Dent 2012; 4: e48-e53

https://doi.org/10.4317/jced.50592

3. Ganss C. Definition of erosion and links to tooth wear. Monogr Oral Sci. 2006; 20:9-16.

https://doi.org/10.1159/000093344

4. Wetselaar P, van der Zaag J, Lobbezoo F. Tooth wear, a proposal for an evaluation system. Ned Tijdschr Tandheelkd. 2011;118:324-28. https://doi.org/10.5177/ntvt.2011.06.10220

5. Lussi A, Carvalho TS. Erosive tooth wear: a multifactorial condition of growing concern and increasing knowledge. Monogr Oral Sci. 2014; 25:1-15.

https://doi.org/10.1159/000360380

6. Daly RWR, Wan Zaripah Wan Bakar, Adam Husein, Noorliza Mastura Ismail, Bennet T. Amaechi. The study of tooth wear patterns and their associated aetiologies in adults in Kelantan, Malaysia. Arch Orofac Sci. 2010; 5:47-52.

7. Al-Zarea BK. Tooth Surface Loss and Associated Risk Factors in Northern Saudi Arabia. ISRN Dent. 2012:161565.

https://doi.org/10.5402/2012/161565

8. Hegde MN, Hegde P, D'souza SP, Attavar A. Prevalence of tooth wear in south west coastal population of India. Int J Primary Health Care. 2016; 6(4):47-56.

9. Al-Omiri MK, Lamey PJ, Clifford T. Impact of tooth wear on daily living. Int J Prosthodont 2006; 19: 601-605.

https://doi.org/10.1080/14767050600900996

10. Fung, A. and Messer, L.B. (2013), Tooth wear and associated risk factors in a sample of Australian primary school children. Aust Dent J, 58:235-45.

https://doi.org/10.1111/adj.12055

11. Khan MW, Mahmood HN, Fatima A. Prevalence of Tooth Wear in Permanent Dentition of Pakistani Adults. Pak J Med Sci. 2018;12:1082-3.

12. Mulic A, Tveit AB, Songe D, Sivertsen H, Skaare AB. Dental erosive wear and salivary flow rate in physically active young adults. BMC Oral Health. 2012;12:8.

https://doi.org/10.1186/1472-6831-12-8

13. Mulic A, Skudutyte-Rysstad R, Tveit AB, Skaare AB. Risk indicators for dental erosive wear among 18-yr-old subjects in Oslo, Norway. Eur J Oral Sci. 2012; 120:531-8.

https://doi.org/10.1111/j.1600-0722.2012.00997.x

14. Isaksson H, Birkhed D, Wendt L-K, Alm A, Nilsson M, Koch G. Prevalence of dental erosion and association with lifestyle factors in Swedish 20-year olds. Acta Odontol Scand.2014; 72:448-57. https://doi.org/10.3109/00016357.2013.859727
Evaluation of tooth wear and its causative risk factors amongst patients attending dental hospital of Karachi

15. Attin T, Wegehaupt FJ. Methods for assessment of dental erosion. Monogr Oral Sci. 2014; 25:123-42. https://doi.org/10.1159/000360355

16. Bardsley PF. The evolution of tooth wear indices. Clin Oral Investig. 2008; 12(Suppl1): S15-S19 Review. https://doi.org/10.1007/s00784-007-0184-2

17. Margaritis V, Nunn J. Challenges in assessing erosive tooth wear. Monogr Oral Sci. 2014; 25:46-54. https://doi.org/10.1159/000359937

18. Smith BG, Knight JK. An index for measuring the wear of teeth. Br Dent J. 1984;156:435-38.

https://doi.org/10.1038/sj.bdj.4805394

19. Toufique H, Nisar N, Saadat S. Tooth Wear And Its Related Factors: Findings From A Hospital Based Study. Pak Oral Dent J. 2017: 37:45964.

20. Daly R, Wan Bakar W, Husein A, Ismail N, Amaechi B. The study of tooth wear patterns and their associated aetiologies in adults in Kelantan, Malaysia. Arch Orofac Sci. 2010;5:47-52.

21. Que K, Ruan J, Fan X, Liang X, Hu D. A multi-centre and crosssectional study of dentine hypersensitivity in China. J Clin Periodontol 2010; 37: 631-37.

https://doi.org/10.1111/j.1600-051X.2009.01513.x

22. Wetselaar P, Vermaire J, Visscher C, Lobbezoo F, Schuller A. The Prevalence of Tooth Wear in the Dutch Adult Population. Caries Res. 2016; 50:543-550.

https://doi.org/10.1159/000447020

23. Van'tSpijker A, Rodriguez C. Kreulen M, Bronkhorst W. Bartlett, N.H. Creugers, Prevalence of tooth wear in adults, Int J Prosthodont Restor Dent. 2009;22:35-42.

24. Wirdatul, R. D., Wan Zaripah, W. B., Husein, A., Mastura, N. I., and Amaechi, B. Tooth wear patterns and their associated aetiologies in adults in Kelantan, Malaysia. Arch Orofac Sci. 2010; 5:47-52.

25. Attin T, Weiss K, Becker K, Buchalla W, Wiegand A: Impact of modified acidic soft drinks on enamel erosion. Oral Dis. 2005; 11:712.

https://doi.org/10.1111/j.1601-0825.2004.01056.x

26. Bartlett DW, Fares J, Shirodaria S, Chiu K, Ahmad N, Sherriff M: The association of tooth wear, diet and dietary habits in adults aged 18-30 years old. J Dent. 2011;39: 811-816.

https://doi.org/10.1016/j.jdent.2011.08.014

27. Moazzez R, Smith BG, Bartlett DW: Oral pH and drinking habit during ingestion of a carbonated drink in a group of adolescents with dental erosion. J Dent. 2000;28:395-97.

https://doi.org/10.1016/S0300-5712(00)00020-8

28. Addy M. 2000 Dentine hypersensitivity: definition, prevalence, distribution and aetiology. In: Tooth wear and sensitivity: clinical 
Shahab A/ Wali A/ Siddiqui TM/

Hamed M/ Aslam K

advances in restorative dentistry, Addy M, Embery G, Edgar WM, Orchardson R eds, Martin Dunitz, London, 239-48.

29. Deshpande S. Investigation of Tooth Wear and its Associated Etiologies in Adult Patients Visiting Dental Institute in India. Dentistry 2015; 5:271.

30. Ayer A. Association between Severity of Tooth Wear and Dentinal Hypersensitivity. J Coll Med Sci-Nepal. 2016; 12:94-8. https://doi.org/10.3126/jcmsn.v12i3.15487

31. Idon PI, Esan TA, Bamise CT. Oral health-related quality of life in patients presenting with dentine hypersensitivity: A randomized controlled study of treatment effect. Eur J Gen Dent. 2017;6:99.

32. Ali R, Khan FR. Evaluation of Occlusal Incisal Tooth Wear and Its Influential Factors among Subjects Visiting a University Hospital in Pakistan. J Pak Dent Assoc 2017;26: 5-21.

https://doi.org/10.25301/JPDA.261.15

33. Ahmed H, Sadaf D, Rahman M. Factors associated with NonCarious Cervical Lesions (NCCLs) in teeth. J Coll Physicians Surg Pak. 2009;19:279-8

34. Mushtaq F, Ahmed M. Frequency and etiological factors of noncarious cervical lesions. Pak Oral Dent J. 2016;36:312-18.
Evaluation of tooth wear and its causative risk factors amongst patients attending dental hospital of Karachi

35. Wild YK, Heyman MB, Vittinghoff E, Dalal DH, Wojcicki JM, Clark AL, et al. Gastroesophageal reflux is not associated with dental erosion in children. Gastroenterology 2011; 141: 1605-11.

https://doi.org/10.1053/j.gastro.2011.07.041

36. Cunha-Cruz J, Pashova H, Packard JD, Zhou L, Hilton TJ. Tooth wear: prevalence and associated factors in general practice patients. Community Dent Oral Epidemiol. 2010;38:228-34.

https://doi.org/10.1111/j.1600-0528.2010.00537.x

37. David K, Bhat KM. Prevalence of tooth wear in patients attending the department of periodontics, Manipal college of dental sciences, Manipal. NJIRM.2012;3: 136-141

38. Hanif A, Rashid H, Nasim m. Tooth Surface Loss Revisited: Classification, Etiology And Management. J Res Dent 2015:3:37-43. https://doi.org/10.4103/2321-4619.156643

39. Meshramkar R , Lekha K., Gouri V Anehosur, Ramesh K. Nadiger. A Clinical Survey to Assess Type and Severity of Tooth Wear in Geriatric Patients. ARC J Dent Sci. 2017;2:1-3. 